\title{
IDENTIFICAÇÃO, QUANTIFICAÇÃO E CLASSIFICAÇÃO DOS RESÍDUOS SÓLIDOS DE UMA FÁBRICA DE MÓVEIS
}

\author{
Identification, quantification and classification of solid sawed \\ wood from a furniture industry
}

\section{Pedro Altamir Kozak ${ }^{\mathrm{a}}$, Alison Moura Cortez ${ }^{\mathrm{b}}$, Waldir Nagel Schirmerc, Marcos Vinicius Winckler Caldeira ${ }^{\mathrm{d}}$, Rafaelo Balbinot ${ }^{\mathrm{e}}$}

\footnotetext{
a Engenheiro Ambiental. Irati, PR - Brasil, e-mail: pedrokozak@yahoo.com.br

b Engenheiro Ambiental. Irati, PR - Brasil, e-mail: cortez.ambiental@yahoo.com.br

${ }^{c}$ Engenheiro químico. Prof. Adjunto da Universidade Estadual do Centro-Oeste. Irati, PR - Brasil, e-mail: wanasch@yahoo.com.br.

d Engenheiro florestal. Prof. Dr. Coordenador do Curso de Engenharia Florestal da Universidade Federal do Espírito Santo. Alegre, ES - Brasil, e-mail: caldeiramv@yahoo.com.br

e Engenheiro florestal. Prof. Colaborador da Universidade Estadual do Centro-Oeste. Irati, PR - Brasil, e-mail: rbalbinot@yahoo.com.br
}

\begin{abstract}
Resumo
O setor de móveis é um grande consumidor de matérias-primas e, como tal, gerador de expressiva quantidade de resíduos sólidos, líquidos e atmosféricos. A natureza dos resíduos depende, exclusivamente, do processo industrial em questão. A fabricação de móveis esteve sempre relacionada à maior geração de resíduos sólidos, principalmente nas etapas de beneficiamento da madeira. No entanto, raramente essas unidades de produção dispõem de um plano de gestão para esse tipo de resíduo. Neste sentido, o presente trabalho objetiva identificar, quantificar e classificar, de acordo com normas pertinentes da ABNT, os resíduos sólidos provenientes de uma fábrica de móveis localizada na cidade de Irati, PR. Propõe, ainda, maneiras de reutilização e reciclagem desses resíduos. Para tanto, a metodologia empregada foi a coleta de informações dos resíduos, do processo produtivo e das matérias-primas utilizadas. Para realizar a classificação, utilizou-se a norma NBR 10004, de 2004. Os resultados indicaram que os resíduos de maior geração são, de fato, os de madeira (pó, cepilhos e aparas de painéis); em menor quantidade, há geração de resíduos de plásticos, metais e $\mathrm{papel} / \mathrm{papelão}$. Têm-se ainda a geração de resíduos perigosos, como solventes orgânicos e borra de tinta. Pode-se concluir que a quantidade de resíduos gerada por uma única empresa pode não ser expressiva, mas no contexto nacional se torna um problema de consideráveis proporções.
\end{abstract}

Palavras-chave: Indústria moveleira; Resíduos sólidos e líquidos; Gestão de resíduos. 


\begin{abstract}
The furniture sector is a great consumer of raw materials and, thus, generator of an expressive quantity of solid, liquid and atmospheric wastes. The waste nature exclusively depends on the focussed industrial process. The furniture production has always been related to the largest generation of solid waste, mainly in phases of wood processing. Though, these production units rarely dispose a management plan for this kind of waste. Therein, the current work objects to identify, quantify and classify, according to ABNT standards, the solid wastes from a furniture industry located in the municipality of Irati, PR. Moreover, it is proposed ways to reuse and recycle this waste. Thereby, the proposed methodology was to collect information about waste, productive process and use of raw materials. In order to classify then, the NBR 1004 (2004) was used. The results indicated that the most typical waste were, indeed, wood pieces (dust, jointers and panels chips); and in less quantity, there were plastic, metals and papers wastes as integrated items in the processing. There were also identified additionally dangerous wastes, as organic solvents and ink dregs. It is concluded that the quantity of generated wastes by only one company can not be expressive, but in the national context it turns a significant problem.
\end{abstract}

Keywords: Furniture industry; Solid and liquid wastes; Waste management.

\title{
INTRODUÇÃO
}

O crescimento desordenado da população mundial desencadeou um aumento excessivo no uso de energia e no consumo de matérias-primas, o que ocasionou, por conseqüência, um aumento cada vez maior na geração de resíduos. Essa geração, de maneira geral, ocorre em todos os processos de utilização e transformação de matérias-primas. Nesse caso, os resultados dessa transformação geram, incondicionalmente, resíduos sólidos, líquidos e atmosféricos. Braga, Hespanhol e Conejo (2005) comentam que, com a implantação de políticas ambientais, a sociedade e os indivíduos passam a ter à sua disposição um ambiente potencialmente capaz de propiciar a satisfação de uma série de demandas antes impossíveis de serem atendidas. Dentre elas estão as questões ligadas à produção e à eficiência do processo produtivo, como a redução das perdas de matérias e equipamentos em um ambiente menos agressivo. Em conseqüência dos processos econômicos esse novo ambiente passa a constituir um bem de mercado.

A natureza dos resíduos depende exclusivamente do processo industrial em questão. A fabricação de móveis esteve sempre relacionada à geração de resíduos sólidos, principalmente nas etapas de beneficiamento da madeira. No entanto, raramente, essas unidades de produção dispõem de um plano de gestão para esse tipo de resíduo.

Os resíduos sólidos são definidos, segundo a Associação Brasileira de Normas Técnicas (ABNT, NBR 10.004, 2004a), como:

Todo resíduo nos estados sólido e semi-sólido resultam de atividades de origem industrial, doméstica, hospitalar, comercial, agrícola, de serviços e de varrição. Ficam incluídos nesta definição os lodos provenientes de sistemas de tratamento de água, aqueles gerados em equipamentos e instalações de controle de poluição, bem como determinados líquidos cujas particularidades tornem inviável o seu lançamento na rede pública de esgotos ou corpos de água, ou exijam, para isso, soluções técnicas e economicamente inviáveis em face à melhor tecnologia disponível. 
Ainda, de acordo com essa mesma norma, os resíduos podem ser classificados nas seguintes classes:

I - perigosos;

IIA - não perigosos; e

IIB - inertes.

Essa classificação acontece por meio da identificação do processo ou atividade que lhe deu origem, seus constituintes, suas características físicas, químicas e biológicas e a comparação com listagens de resíduos já conhecidos.

O BNDES (2007), classifica a indústria de móveis com base nas matérias-primas predominantes. As categorias básicas são: móveis de madeira, que constituem o principal segmento, representando $72 \%$ da produção total; os móveis de metal, representando $12 \%$; e o restante, confeccionados por outros materiais, que reúne colchoarias e persianas. Segundo Nahuz (2005), a indústria moveleira integra uma grande variedade de materiais, sendo os principais: materiais derivados da madeira (madeira bruta, painéis, lâminas e derivados); metais (principalmente alumínio, aço e latão, utilizados em puxadores, dobradiças, corrediças, etc.); vidros e cristais; produtos químicos (tintas, solventes, colas, vernizes, etc.); plásticos (fitas de borda, lâminas, puxadores, deslizadores, etc.) e tecidos e couros (naturais e sintéticos). Esta mescla de materiais utilizados tem como conseqüência uma grande e complexa diversidade de resíduos, que, pela falta de um plano de gestão adequado, acabam dificultando programas de reúso, reciclagem e outras formas de destinação final adequada.

Segundo ABIMÓVEL (2006), no levantamento efetuado na Relação Anual de Informações Sociais (RAIS), do Ministério do Trabalho, em 2004, existem no Brasil cerca de 16.104 empresas do setor moveleiro que geram 206.352 empregos com faturamento anual de 12,5 bilhões de reais. Nahuz (2005) admite, porém, que o número de empresas pode chegar a 50.000, devido à atuação informal. Com base nesses números, pode-se ter uma idéia do volume de resíduos gerados somente neste setor.

Por utilizar, principalmente, produtos derivados da madeira (um recurso natural renovável), não é dada à indústria da madeira a devida importância no que se refere às questões ambientais. No país, estima-se que não chegam a 5\% as empresas que praticam algum esquema de conservação ambiental, com prevenção de impactos ambientais causados por seus processos produtivos, matérias-primas, insumos e componentes utilizados, pela geração de resíduos e pela disposição destes (NAHUZ, 2005). Porém, devido ao elevado custo das matérias-primas e componentes utilizados, a indústria moveleira vem amadurecendo a idéia de otimizar o uso desses materiais; ainda assim, mais por questões econômicas do que propriamente ambientais.

Considerando a importância do setor moveleiro no cenário econômico brasileiro, os aspectos e impactos ambientais, os custos na recuperação dos ambientes degradados e os benefícios às organizações, a gestão ambiental emerge na indústria de móveis como forma de redução de custos no processo produtivo, destinação de seus resíduos e, ainda, como ferramenta de competitividade de mercado. Segundo a norma ISO 14.001 (2004b), um dos requisitos na implantação do Sistema de Gestão Ambiental (SGA) em uma organização é o estabelecimento e a implementação de procedimento de identificação e controle dos aspectos ambientais relacionados com suas atividades.

Desse modo, o presente trabalho tem como objetivo identificar, classificar e quantificar os resíduos sólidos provenientes do processo produtivo de uma fábrica de móveis de pequeno porte, localizada no município de Irati, Estado do Paraná, por meio da utilização da norma da ABNT NBR 10.004 (2004a). O trabalho abrange todo o processo produtivo da empresa e sugere formas de gestão. 


\section{MATERIAIS E MÉTODOS}

\section{Descrição do processo industrial}

A empresa enquadra-se como micro empresa e seu processo de fabricação de móveis não é seriado, isto é, os móveis são produzidos sob medida, não possuindo uma linha de produção padrão, caracterizando-se como marcenaria.

O início do processo ocorre com o corte dos painéis de diversos tamanhos em peças prontas para a confecção dos móveis (o corte é feito com serra circular). Após cortadas, as peças vão para o setor de fresagem, onde máquinas (tupia, serra fita e brocas) fazem operações como arredondamento de bordas, cantos e entalhes de superfícies das peças.

Quando as peças estão no formato desejado, elas passam para a furação e depois para as bancadas de montagem. As peças que não possuem revestimento são lixadas por lixadeiras mecânicas antes de ir para o setor de pintura, onde é aplicado primeiro o fundo e depois a tinta. A pintura é realizada com pistola manual de ar comprimido.

As peças prontas passam pelo setor de controle de qualidade e expedição. Não há o setor de embalagem como aquele verificado numa produção em série.

A seqüência do processo de produção de móveis também pode ser verificada por meio do fluxograma (Figura 1).

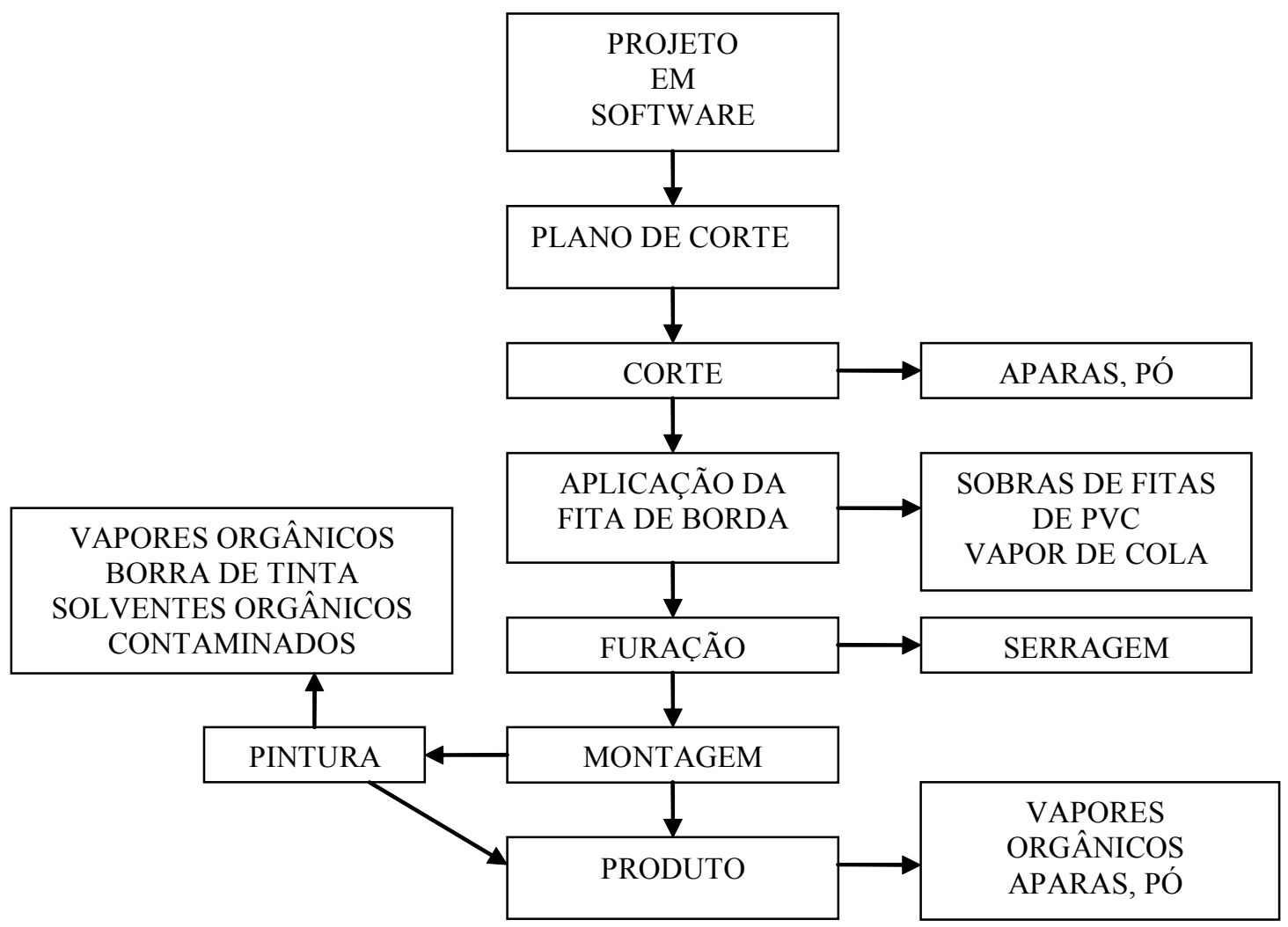

FIGURA 1 - Fluxograma do processo de fabricação de móveis

Figure 1 - Flowchart of the furniture production 


\section{Matérias-primas utilizadas}

As matérias-primas utilizadas pela indústria são compostas por uma grande mescla de materiais produzidos por outras indústrias. A principal matéria-prima é a madeira, sob a forma de chapas. Os materiais derivados da madeira utilizados pela empresa são: madeira maciça (Pinus sppp e madeiras nobres), aglomerados, compensados, $\mathrm{MDF}^{1}$ (mais utilizado), $\mathrm{OSB}^{2}$ e lâminas decorativas.

Já os materiais de origem "não florestal", compostos por metais, plásticos e vidros são utilizados como complementos na fabricação. O metal e o vidro são utilizados em portas, pés, puxadores, fixação das peças e como complemento do móvel. O plástico é utilizado em puxadores, deslizadores, fitas de bordas e lâminas para revestimento mais resistente.

Os materiais empregados no acabamento e revestimento são as tintas (aqui compreendendo seladores, fundos, "primers", tingidores, lacas e poliuretânicos), solventes orgânicos, vernizes, colas e lixas.

\section{Identificação e quantificação dos resíduos encontrados na fábrica}

Durante o inventário dos resíduos, o nível de produção estava em torno de $50 \%$ do potencial máximo. Os resíduos gerados na empresa foram divididos em sólidos e líquidos (esta divisão foi feita para melhor quantificá-los e caracterizá-los).

Primeiramente, propôs-se a estimativa dos resíduos gerados por meio de amostragens, utilizando-se para isso, a NBR 10.007 (2004c), amostragem de resíduos sólidos.

A quantificação e a identificação dos resíduos foram efetuadas com medições diretas na fonte geradora em cada término do expediente de trabalho, durante quatro semanas seguidas. $O$ levantamento incluiu também informações sobre o processo produtivo, as matérias-primas e insumos utilizados no período, a identificação de substâncias que conferem periculosidade aos resíduos e de que forma a empresa tratava o tema 'geração de resíduos'.

Segundo a NBR 10.004 (2004a), os resíduos são classificados em função de suas propriedades físico-químicas e por meio da identificação dos contaminantes presentes. A segregação dos resíduos na fonte geradora e a identificação da sua origem são partes integrantes dos laudos de classificação, nos quais a descrição de matérias-primas, de insumos e do processo gerador do resíduo devem ser explicitados.

A classificação dos resíduos foi efetuada por meio de consulta direta às listagens da norma NBR 10.004 (2004a).

\section{Panorama ambiental da empresa}

Todos os resíduos gerados em uma empresa, a princípio, devem ser destinados de forma que causem o menor impacto possível ao meio ambiente e à saúde pública. No entanto, devido à falta de profissionais capacitados, os resíduos, muitas vezes, são dispostos de forma inadequada, favorecendo a degradação ambiental.

Na empresa avaliada, normalmente ocorre a separação dos resíduos por setor, mas sem haver nenhum controle destes. Comumente, os resíduos não são identificados, caracterizados, acondicionados, transportados e dispostos conforme legislação e/ou determinação do órgão ambiental. Não há, também, classificação de acordo com a norma NBR - 10.004/04 da ABNT e a equipe de trabalho da empresa não está ciente das responsabilidades, quanto à disposição final.

Além disso, a empresa não possui um profissional responsável pelo setor ambiental e não tem programas de redução, reutilização e reciclagem.

${ }^{1}$ MDF é a sigla em inglês para Medium Density Fiberboard que, traduzindo, quer dizer "chapa de fibra de madeira de média densidade."

2 OSB é a sigla em inglês para Oriented Strand Board que, traduzindo, quer dizer "chapa de filamentos de madeira orientados." 


\section{RESULTADOS E DISCUSSÃO}

\section{Resíduos sólidos}

Entre os vários resíduos sólidos encontrados na fábrica, os de maior geração foram mesmo os de madeira como pó, cepilhos e aparas de painéis (as aparas compreendem as sobras laterais das chapas após a sua manufatura).

A Tabela 1 apresenta a quantidade de resíduos gerados no período de um mês de trabalho, com seus respectivos percentuais.

TABELA 1 - Quantidade total de resíduos sólidos mensais gerados na empresa

Table 1 - Total amount of solid wastes monthly generated in the plant

\begin{tabular}{lcc}
\hline Tipo de resíduo & Quantidade $\mathbf{( K g )}$ & Percentual (\%) \\
\hline Aparas de painéis & 874,20 & 63,08 \\
Cepilho & 227,50 & 16,42 \\
Pó & 183,00 & 13,21 \\
Plástico & 24,80 & 1,79 \\
Vidro & 0,00 & 0,00 \\
Papel & 7,80 & 0,56 \\
Resíduo de varrição & 41,50 & 3,00 \\
Metal & 18,00 & 1,30 \\
Orgânico & 9,00 & 0,65 \\
\hline \multirow{2}{*}{ Total } & $1.385,80$ & 100,00 \\
\hline
\end{tabular}

Analisando os dados, pode-se observar que, de fato, houve maior geração de resíduos de madeira. Pode-se observar ainda que o resíduo de aparas obteve maior representatividade; isso se deve em virtude da empresa trabalhar com pouca madeira bruta, mas, principalmente, com lâminas e painéis.

Os $0,65 \%$ de materiais orgânicos são oriundos da alimentação dos funcionários, principalmente cascas de frutas consumidas em intervalos de expedientes. Os resíduos de varrição de fábrica, originários da limpeza, correspondem a 3\%. Observou-se também que o pó de madeira é o maior contribuinte neste tipo de resíduo.

\section{Resíduos líquidos}

Os resíduos líquidos gerados compreendem, basicamente, borra de tinta e solventes orgânicos. Como a empresa ainda não possui cabine de pintura, não há geração de água ou outro líquido contaminado usado na lavagem de particulados. Além disso, o processo utiliza uma grande quantidade de painéis revestidos, que não necessitam de pintura. A produção de móveis, dessa maneira, gera menos resíduos líquidos, como se pode observar na Tabela 2.

TABELA 2 - Quantidade total de resíduos líquidos gerados no período avaliado

Table 2 - Total amount of liquid wastes generated during the period

\begin{tabular}{lll}
\hline Resíduos & Quantidade (L) & Percentual (\%) \\
\hline Borra de tinta & 6 & 37,50 \\
Solvente (Thinner) & 10 & 62,50 \\
Total & 16 & 100,00 \\
\hline
\end{tabular}


Lima (2005) encontrou em pequenas empresas de produção de móveis retilíneos a geração de 85\% de solvente de tinta e $6 \%$ de borra de tinta, o que difere um pouco dos valores aqui encontrados. Essa diferença, provavelmente, deve-se ao fato de a preparação da tinta, no caso da fábrica avaliada, ser realizada sem nenhuma medição dos componentes adicionados (solventes e catalisadores), sendo estes colocados manualmente pelo operador de pintura. O ponto ideal e a quantidade total necessária da mistura são decorrentes apenas da experiência do funcionário, o que acarreta maior perda de insumos e desuniformidade do processo.

\section{Classificação}

Antes de iniciar a classificação dos resíduos sólidos gerados em uma organização é importante observar que, além daqueles que estão em estado sólido e semi-sólido, há substâncias no estado líquido que são consideradas pela norma ABNT NBR 10.004 (2004a) como sendo sólidos. De acordo com Braga et al. (2005), a norma classifica os resíduos em três classes, considerando a possibilidade de tratamento e disposição dos resíduos em condições satisfatórias dos pontos de vista ambiental, econômico e sanitário.

$\mathrm{Na}$ Tabela 3 pode-se notar quais são os resíduos produzidos, suas propriedades físicoquímicas e a classe de enquadramento.

TABELA 3 - Classificação dos resíduos segundo a norma NBR 10.004 (2004a)

Table 3 - Wastes classification according to NBR 10.004 (2004a)

\begin{tabular}{lll}
\hline Tipo de resíduo & Classes & Principais propriedades \\
\hline Madeira & IIA - Não-perigosos & Degradabilidade, combustibilidade \\
Papel e papelão & IIA - Não-perigosos & Degradabilidade, combustibilidade \\
Orgânicos & IIA - Não-perigosos & Degradabilidade \\
Metais & IIA - Não-perigosos & Oxidação \\
Borra de tinta & I - Perigosos & Toxicidade \\
Solvente & I - Perigosos & Toxicidade, corrosividade, inflamabilidade \\
\hline
\end{tabular}

Fonte: NBR 10.004 (2004a).

Qualquer resíduo classificado como não perigoso que entra em contato com substâncias constantes nos anexos D ou E da norma (substâncias agudamente tóxicas e substâncias tóxicas, respectivamente) ou com resíduos perigosos são como tal denominados. Portanto, materiais contaminados por solventes e outras substâncias utilizadas na pintura de móveis serão considerados resíduos perigosos (NBR 10.004, 2004a).

Os resíduos metálicos encontrados na empresa são representados, basicamente, por embalagens de substâncias empregadas na pintura. Essas substâncias, por possuírem metais pesados e compostos orgânicos voláteis, são consideradas perigosas, apresentando risco à saúde do trabalhador e ao ambiente. Na prática, o que se faz é a reciclagem normal do metal por empresas terceirizadas, que se encarregam desse processo.

\section{Gestão dos resíduos}

Gerenciamento de resíduos sólidos industriais é o processo que compreende a segregação, o acondicionamento, a coleta, o transporte, o armazenamento, a reciclagem, o tratamento e a destinação final. A resolução CONAMA, nº ${ }^{\circ}$ 06, de 15 de junho de 1988, estabelece que todas as indústrias geradoras de resíduos perigosos devem apresentar, ao órgão ambiental competente, informações sobre a geração, características e destino final de seus resíduos. No estado do Paraná, a lei de no 12.493 , de 1999, estabelece que todas as empresas com atividades geradoras de resíduos sólidos são responsáveis

Rev. Acad., Ciênc. Agrár. Ambient., Curitiba, v. 6, n. 2, p. 203-212, abr./jun. 2008 
pelo seu gerenciamento, atendendo às normas aplicáveis da ABNT e do Instituto Ambiental do Paraná (IAP). Ela proíbe, em todo o Estado, a disposição final de resíduos sólidos por meio da queima a céu aberto e pelo lançamento em corpos d'água, manguezais, terrenos baldios, redes públicas, poços e cacimbas, mesmo que abandonados.

Para facilitar a segregação, a coleta, o transporte e a reciclagem, a Resolução CONAMA n ${ }^{\circ}$ 275 de 25 de abril de 2001, estabelece código de cores para os diferentes tipos de resíduos, a ser adotado na identificação de coletores.

Com a análise das tabelas 1 e 3 , pode-se dimensionar o tamanho dos coletores e os códigos de cores, necessitando, neste caso, de instalação dos seguintes padrões de cores: azul (papel/papelão), vermelho (plástico), amarelo (metal), preto (madeira), laranja (resíduos perigosos), marrom (resíduos orgânicos) e cinza (resíduo geral não reciclável ou misturado, ou contaminado não passível de separação). Já a quantidade e a distribuição de coletores na empresa devem ser realizadas por meio de um estudo mais detalhado das instalações, para que não ocorram problemas à produção e facilitem o descarte dos resíduos, porém pode-se, antecipadamente, afirmar que só há necessidade de instalação de coletor de resíduos perigosos no setor de pintura, dispensando-o no caso de madeira.

Buscando a minimização da degradação ambiental, a diminuição dos riscos potenciais à saúde pública, a redução dos custos econômicos e considerando o que dispôs as normas e requisitos legais, propõe-se o gerenciamento dos resíduos de acordo com a classificação realizada. Sendo assim, os resíduos enquadrados nas classes IIA e IIB podem ser reutilizados ou reciclados, dependendo das possibilidades ambientais e econômicas. Os resíduos perigosos (classe I) também podem ser reutilizados ou reciclados, porém há maior custo econômico, caso contrário deve ser disposto em aterro industrial ou tratados e dispostos em aterro sanitário.

Os materiais constituídos por plásticos, papel e papelão, metais, vidros e também aqueles resíduos não caracterizados, devem ser coletados de forma seletiva pelo serviço de limpeza pública (já implantado no município de Irati) para posterior reciclagem e destinação final. As lixas ainda não têm solução definida, sendo essas destinadas ao aterro sanitário.

A borra de tinta deve ser coletada, tratada e destinada por empresa terceirizada especializada neste tipo de resíduo. Vale ressalvar que a empresa geradora tem a obrigação de conhecer os processos utilizados no tratamento e qual o destino final de seus resíduos. O solvente orgânico pode ser reutilizado na limpeza dos equipamentos de pintura. Depois de exaurido, o solvente também pode ser coletado, tratado e destinado por empresa terceirizada, especializada neste tipo de resíduo.

Com relação as embalagens de tintas e solventes, antes de enviá-las para a reciclagem, é aconselhável deixá-las viradas com a tampa aberta para que o excesso escorra e acumule em um recipiente único e impermeável para posterior destinação de forma adequada. Não é permitida a reutilização das embalagens por oferecerem risco à saúde e ao meio ambiente.

Pode-se conseguir a redução ou a total eliminação de resíduos perigosos por meio da substituição de tintas e colas de bases orgânicas por outras à base d'água. Esta substituição não compromete a qualidade do produto final, porém possui maior custo financeiro. Freeman (1995) e USEPA (1994, apud Lima, 2005) indicam, além da tinta à base d'água, o uso de tintas por cura ultravioleta (UV), poliéster e poliuretano (PU), que possuem baixo conteúdo de compostos orgânicos voláteis (COV), e alertam para o uso da nitrocelulose, que além de ter um alto volume de COV, é tóxica e inflamável.

Os resíduos de madeira podem ser utilizados de várias maneiras, a depender da viabilidade econômica e ambiental. Para Brand et al. (2002), a quantidade disponibilizada é um dos fatores que determinam a potencialidade de uso dos resíduos da madeira e deve ser analisado em termos de sua geração e utilização. Os cepilhos, as aparas de painéis, o pó e outros materiais derivados da madeira podem ser utilizados na geração de energia pela queima em caldeiras ou em fornos de olarias. A eficiência na geração de energia, segundo Torreira (1995) e Krogh (1982 apud Silva, 2001), está intimamente ligada ao tamanho da partícula a ser queimada, sendo o pó mais eficiente, por necessitar de menor quantidade de ar e queimar mais rapidamente.

Pode-se ainda utilizar os resíduos de madeira na confecção de briquetes. Essa utilização tem suas vantagens e desvantagens, dependendo de qual processo for utilizado para sua aplicação e da distância de transporte até o local da queima. Segundo Martins (1980, apud Silva, 2001), a utilização 
da madeira na geração de energia tem a vantagem de ser renovável, porém apresenta baixo poder calorífico e grande volume. Se for considerar sua utilização em fornos e lareiras, a briquetagem tornase mais vantajosa, devido à diminuição do volume e o aumento do tempo de queima. No caso de emprego em caldeiras de alta eficiência, localizadas nas proximidades da geração dos resíduos, é aconselhável a utilização do próprio pó sem nenhum pré-tratamento.

Lima e Silva (2005) afirmam que os resíduos da madeira podem ser usados também como cargas para compostos poliméricos, na confecção de chapas de partículas e na produção de polpa de papel.

As aparas de painéis podem ter usos mais nobres, por meio da confecção de peças de artesanato por alunos da APAE (Associação de Pais e Amigos dos Excepcionais) do município. Neste caso, há necessidade de um convênio entre a empresa e a associação. Recomenda-se, ainda, a instalação de um bom sistema de exaustão, para evitar a poluição do ar interno e prejuízos à saúde do trabalhador. A coleta do pó diretamente da fonte ajuda a melhorar o aproveitamento deste. Além de proporcionar a diminuição dos resíduos de varrição da fábrica, evita que os trabalhadores fiquem expostos a gases tóxicos oriundos dos solventes orgânicos.

As empresas moveleiras que estejam localizadas próximas umas às outras e que possuam um mínimo de organização e disposição podem solucionar os problemas com maior facilidade. De acordo com Lima (2005), em Arapongas (PR) as empresas do ramo moveleiro, com a criação do Centro de Tecnologia em Ação e Desenvolvimento Sustentável (CETEC), estão desenvolvendo ações que melhoram a qualidade ambiental, principalmente no que diz respeito ao destino dos resíduos gerados nas empresas do município.

\section{CONCLUSÕES}

Com relação à análise realizada e os resultados obtidos, pode-se concluir que:

- a maioria dos resíduos gerados é derivada da madeira e é classificada como resíduos classe IIA - não inertes. Estes podem ser usados em outros processos, principalmente na geração de energia;

- os principais resíduos perigosos são os derivados do processo de pintura, mas como a empresa utiliza, na maioria das vezes, painéis revestidos, há pouca geração de resíduos dessa natureza;

- a empresa pode adotar tintas à base d'água, evitando a produção de resíduos perigosos e os gastos com tratamento e destinação final;

- a quantidade de resíduos gerada por uma única empresa pode não ser significativa, mas no contexto nacional se torna um problema de grandes proporções;

- o planejamento no "design" e na produção do móvel deve levar em consideração as dimensões e formas dos painéis utilizados, buscando maximizar seu aproveitamento e, com isto, gerar o mínimo de resíduos decorrentes de sua manufatura.

\section{REFERÊNCIAS}

ASSOCIAÇÃO BRASILEIRA DAS INDÚSTRIAS DO MOBILIÁRIO - ABIMÓVEL. Panorama do setor moveleiro no Brasil: informações gerais. São Paulo: ABIMÓVEL, 2006. 17 p. Disponível em: <www.portalbmk.org.br/publicacoes/arquivos/1171655150.pdf>. Acesso em: 13 ago. 2007. ASSOCIAÇÃO BRASILEIRA DE NORMAS TÉCNICAS. NBR 10004. Resíduos sólidos: classificação. Rio de Janeiro, 2004a.

ASSOCIAÇÃO BRASILEIRA DE NORMAS TÉCNICAS. NBR ISO 14001. Sistema de gestão ambiental: requisitos para uso. Rio de Janeiro, 2004b. 
ASSOCIAÇÃO BRASILEIRA DE NORMAS TÉCNICAS. NBR 10007. Resíduos sólidos: amostragem. Rio de Janeiro, 2004c.

BANCO NACIONAL DE DESENVOLVIMENTO SOCIAL. O setor de móveis na atualidade: uma análise preliminar. Rio de Janeiro: BNDS, 2007. Disponível em: <www.bndes.gov.br/ conhecimento/bnset/set2503.pdf>. Acesso em: 13 ago. 2007.

BRAGA, B.; HESPANHOL, I.; CONEJO, J. G. L. Introdução à engenharia ambiental: o desafio do desenvolvimento sustentável. 2. ed. São Paulo: Pearson Prentice Hall, 2005.

BRAND, M. A. et al. Caracterização do rendimento e quantificação dos resíduos gerados em serraria através do balanço de materiais. Revista Floresta, Curitiba, v. 32, n. 2, p. 247-259, 2002.

BRASIL. Conselho Nacional do Meio Ambiente. Disciplina que no processo de licenciamento ambiental de atividades industriais, os resíduos gerados ou existentes deverão ser objeto de controle específico. Resolução CONAMA n. 006, de 15 de junho de 1988. Lex: Livro CONAMA, Brasília, 2006. 808 p.

BRASIL. Conselho Nacional do Meio Ambiente. Estabelece o código de cores para os diferentes tipos de resíduos, a ser adotado na identificação de coletores e transportadores. Resolução CONAMA n. ${ }^{\circ}$ 275, de 25 de abril de 2001. Lex: Brasília, Livro CONAMA, 2006. p. 808.

FREEMAN, H. M. Industrial pollution prevention handbook. New York: Mc Graw-Hill, 1995.

KROGH, G. Biomassa: uma fonte energética do Brasil para consumo interno e exportação: aplicação de tecnologia avançada no seu aproveitamento para fins energéticos. Brasília: CNI, 1982.

LIMA, E. G. Diagnóstico ambiental de empresas de móveis em madeira situadas no pólo moveleiro de Arapongas - PR. Curitiba, 2005. 150 f. Dissertação (Mestrado de Engenharia Florestal) - Universidade Federal do Paraná, Curitiba, 2005.

LIMA, E. G.; SILVA, D. A. Resíduos gerados em indústrias de móveis de madeira situadas no pólo moveleiro de Arapongas - PR. Revista Floresta, Curitiba, v. 35, n. 1, p.105-116, 2005.

MARTINS, H. Madeira como fonte de energia. Belo Horizonte: Fundação Centro Tecnológico de Minas Gerais, 1980.

NAHUZ, M. A. R. Resíduos da indústria moveleira: a cadeia produtiva de móveis no Brasil. São Paulo: IPT, 2005. (Divisão de Produtos Florestais).

PARANÁ. Secretaria Estadual do Meio Ambiente. Lei no. 12493, de 22 de janeiro de 1999. Estabelece princípios, procedimentos, normas e critérios referentes à gestão dos resíduos sólidos. Diário Oficial, Curitiba, n. 5430, 1999. Disponível em: <http://celepar7cta.pr.gov.br/ SEEG/ s u mula s.nsf/9973229 f 063 f 4 a 8 d 03256 c 2 f 007 a 992 a/ 7658813fa00d0c3803256e990068926c?OpenDocument>. Acesso em: 27 ago. 2007.

SILVA, D. A. Avaliação da eficiência energética em uma indústria de painéis compensado. 2001. 205 f. Tese (Doutorado em Engenharia Florestal) - Universidade Federal do Paraná, Curitiba, 2001.

TORREIRA, R. P. Geradores de vapor. São Paulo: Companhia Melhoramentos e Libris, 1995.

UNITED STATES ENVIRONMENTAL PROTECTION AGENCY - USEPA. Pollution prevention for the wood finishing industry. [S.1.]: Pollution Prevention Workgroup, 1994. 